WellBeing International

WBI Studies Repository

3-1997

\title{
Development of Piagetian Object Permanence in a Grey Parrot (Psittacus erithacus)
}

\author{
Irene M. Pepperberg \\ University of Arizona \\ Mark R. Willner \\ University of Arizona \\ Lauren B. Gravitz \\ Barnard College
}

Follow this and additional works at: https://www.wellbeingintlstudiesrepository.org/acwp_asie

Part of the Animal Studies Commons, Comparative Psychology Commons, and the Other Animal Sciences Commons

\section{Recommended Citation}

Pepperberg, I. M., Willner, M. R., \& Gravitz, L. B. (1997). Development of Piagetian object permanence in grey parrot (Psittacus erithacus). Journal of Comparative Psychology, 111(1), 63.

This material is brought to you for free and open access by WellBeing International. It has been accepted for inclusion by an authorized administrator of the WBI Studies Repository. For more information, please contact wbisr-info@wellbeingintl.org.

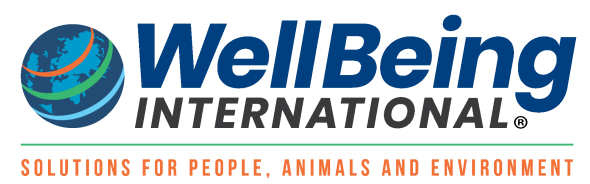




\title{
Development of Piagetian Object Permanence in a Grey Parrot (Psittacus erithacus)
}

\author{
Irene M. Pepperberg*, Mark R. Willner*, and Lauren B. Gravitz ${ }^{\dagger}$ \\ * University of Arizona \\ ${ }^{\dagger}$ Barnard College
}

\begin{abstract}
The authors evaluated the ontogenetic performance of a grey parrot (Psittacus erithacus) on object permanence tasks designed for human infants. Testing began when the bird was 8 weeks old, prior to fledging and weaning. Because adult grey parrots understand complex invisible displacements (I. M. Pepperberg \& F. A. Kozak, 1986), the authors continued weekly testing until the current subject completed all of I. C. Uzgiris and J. Hunt's (1975) Scale 1 tasks. Stage 6 object permanence with respect to these tasks emerged at 22 weeks, after the bird had fledged but before it was completely weaned. Although the parrot progressed more rapidly overall than other species that have been tested ontogenetically, the subject similarly exhibited a behavioral plateau part way through the study. Additional tests, administered at 8 and 12 months as well as to an adult grey parrot, demonstrated, respectively, that these birds have some representation of a hidden object and understand advanced invisible displacements.
\end{abstract}

In children, object permanence-the notion that objects are separate entities that continue to exist when out of sight of the observer-is neither innate nor unitary, but develops over the first 2 years of life (Harris, 1975, 1983; Piaget, 1936/1952, 1937/1954; Sophian \& Sage, 1983). Piaget (1936/1952) was the first to show that object permanence develops in stages and to show the age at which each stage is reached. During Stage 1, children do not search for an object they have seen disappear. ${ }^{1}$ Children eventually pursue such an object, first simply by tracking its movement (Stage 2), then by recovering a partially (Stage 3) and next a fully occluded item (Stage 4) exactly where they see it disappear. Later, children can retrieve an item that has been hidden successively in several locations (i.e., hidden, exposed, and rehidden several times, Stage 5). Finally, a child masters invisible displacements (Stage 6): An object is hidden in a container, the container is moved behind another occluding device, the object is transferred to (placed in or under) this second device, the child is shown that the first container is empty, and the child successfully infers where the object now resides. Although sometimes criticized as too rigid or insensitive to the possibility that environmental stimulation could accelerate cognitive growth (see Bruner, 1964; Steckol \& Leonard, 1981), or as too dependent on physical maturation (Baillargeon, 1987), the Piagetian framework is undeniably useful in tracking the existence of developmental stages.

The Piagetian six-stage framework is also useful for cross-species comparisons (Chevalier-Skolnikoff, 1976): By providing tasks that can be administered with minimal variation to divergent species, this framework ensures that comparative work will not be rendered ambiguous because of significant variations in experimental design across laboratories (see Bateson, 1979; Kroodsma, 1982). Object permanence has thus been examined in nonhuman primates (Antinucci, Spinozzi, Visalberghi, \& Volterra, 
1982; de Blois \& Novak, 1994; Dumas \& Brunei, 1994; Hallock \& Worobey, 1984; Mathieu \& Bergeron, 1981; Mathieu, Bouchard, Granger, \& Herscovitch, 1976; Natale \& Antinucci, 1989; Natale, Antinucci, Spinozzi, \& Poll, 1986; Parker, 1977; Poti, 1989; Redshaw, 1978; Schino, Spinozzi, \& Berlinguer, 1990; Spinozzi, 1989; Spinozzi \& Natale, 1989; Vaughter, Smotherman, \& Ordy, 1972; Wise, Wise, \& Zimmerman, 1974; Wood, Moriarty, Gardner, \& Gardner, 1980), domestic dogs (Canus familiaris, Doré, Fiset, Goulet, Dumas, \& Gagnon, 1996; Gagnon \& Dor6, 1992, 1993, 1994; Triana \& Pasnak, 1981), domestic cats (Felis catus, Doré, 1986, 1990, 1991; Doré et al., 1996; Dumas, 1992; Dumas \& Doré, 1989, 1991; Goulet, Doré \& Rousseau, 1994; Gruber, Girgus, \& Banuazizi, 1971; Thinus-Blanc, Poucet, \& Chapuis, 1982; Triana \& Pasnak, 1981), a hamster (Mesocricetus auratus, Thinus-Blanc \& Scardigli, 1981), and several avian species (Dumas \& Wilkie, 1995; Etienne, 1973a, 1973b; Funk, 1996; Pepperberg \& Funk, 1990; Pepperberg \& Kozak, 1986). Great apes, psittacids, and possibly dogs reached Stage 6 object permanence, whereas cats, monkeys, ring doves (Slreptopelia risoria), hamsters, and domestic chickens (Gallus gallus) apparently did not. ${ }^{2}$ Most avian studies have tested adult subjects and thus did not track the age at which Piagetian stages occurred or the duration of each stage (but see Funk, 1996). In particular, few studies have compared the ontogeny of object permanence in birds and mammals. Given the differences between psittacine and mammalian developmental timelines, our two goals were to (a) assess the developmental rate of a grey parrot (Psittacus erithacus), a species that appears to succeed on Stage 6 tasks (Pepperberg \& Funk, 1990; Pepperberg \& Kozak, 1986), and (b) compare its developmental rate to that of mammals.

Ontogenetic comparisons of basic cognitive capacities such as object permanence are important for two reasons (Antinucci, 1990; Gagnon \& Doré, 1994). First, such studies examine the process whereby cognitive mechanisms and their underlying structures become integrated or differentiated; thus, multiple comparisons during development may aid identification of these mechanisms and structures. Second, investigating developmental processes may enable researchers to understand the form and function of the final mechanisms and structures and may possibly lead to knowledge of their evolution.

\section{Method}

\section{Subjects and Housing}

The primary subject was a grey parrot, Griffin, who was 8 weeks old at the start of the project; he had been obtained from his breeder a few days previously. He was neither fledged (had no wing, tail, or body feathers) nor completely weaned (i.e., he was hand fed twice a day), although he ate some foods on his own. We would have preferred to begin studying Griffin even earlier, but removing him from the breeder prior to this age would have jeopardized his survival. When not napping, in sessions, or being carried by humans, he spent his days in the company of two adult grey parrots and several humans in a large laboratory; birds were restricted to specific areas in this room. When humans were absent and during sleeping hours, Griffin was confined to a brooder ("Pet"iatric Supply, Model NH-II, Wichita, KS) prior to fledging and in a weaning cage $(38 \times 71 \times 56 \mathrm{~cm})$ after fledging; the cage and brooder were in a room separate from the main laboratory. Harrison's High Potency Bird Diet (HBD, Inc., Lake Worth, FL) and water were available continuously; fruit, vegetables, dried pastas, cereals, and Earth's Best baby food and Gerbers juices were provided when testing was not in progress. Hand feeding (Harrison's Juvenile Formula, HBD, Inc., Lake Worth, FL) occurred twice daily, at about 9 a.m. and 9 p.m. Griffin experienced scheduled play sessions outside of testing: Humans sat with him on a large towel on the floor of his room and presented various items (e.g., small wooden spools, beads, and plant stakes; plastic animals, boxes, barrels, cups, rings; pieces of index cards; and pen caps) with which he could engage in various activities (e.g., chewing, throwing, chasing). He was often given a few seeds and nuts during these sessions. We were also concurrently studying his response to mirrors (Pepperberg, Willner, Gupta, \& Meister, 1996). 
A second grey parrot, Alex, who had been the subject of a previous object permanence study (Pepperberg \& Kozak, 1986), was also the subject of one task (Task 16) and several control trials (Tasks 14a, 15a, and S). At the time of the present experiment, he was 19.5 years old. His housing conditions have been described previously (e.g., Pepperberg, 1992).

We recognize that using a single subject prevents us from claiming that our data represent the speciestypical course of development. Recruiting multiple grey parrots of an appropriate age is, however, extremely difficult: (a) Reputable breeders do not allow outsiders to handle unweaned birds because of the fragility of chicks that are less than 12 weeks old and the possibility of introducing disease into the aviary, and (b) grey parrots may not adapt to multiple successive owners; thus, purchase of birds for use in such a study, with intent of resale, would be unethical. Nevertheless, if a single subject reliably performs a given task at a particular age, the tested aptitude is within the capacity of the species at that point in development. Negative results from one subject, however, do not necessarily imply lack of such an aptitude at that stage for the species as a whole (Triana \& Pasnak, 1981). Thus, although individual differences are likely in grey parrots, the results of our single-subject study can provide a baseline for future research and permit preliminary cross-species comparisons.

\section{Apparatus; Covers and Search Items}

We used plastic boxes, cups, toy barrels, and pieces of paper towel or construction paper as screens. Paper pieces $\left(\sim 6.5 \mathrm{~cm}^{2}\right)$ were slightly crumpled; thus, the presence of a hidden object could not be determined by observation. Except for Task 5 (see below), we used identical types of screens in any given trial that required multiple covers; we varied screens between trials to deter habituation and cueing. Griffin's mode of removing a nonrigid screen (extending his head as far as his neck could stretch, grasping a portion of the screen with his beak and pulling) was not suited to the use of cloth covers. He could, however, grasp a box edge or a piece of paper for removal in a single motion.

We hid a variety of small toys similar to those used in play sessions (beads, key chain, pen caps, etc.) and some foods (nuts, seeds). Correct responses enabled Griffin to eat the food, interact with the toy, or pick up a different item. Many tasks were executed at least once with nonfood items; Griffin's performance did not differ between food and nonfood trials. Odor cues were therefore unlikely to be of particular importance (see Procedural Difficulties for a full discussion). In some cases, he refused food he had uncovered and interacted with a nonfood item instead.

\section{Tasks}

For three reasons, we primarily used Uzgiris and Hunt's (1975) Scale 1 tasks (described below). First, the scale directly measures competence levels through performance on 15 tasks of increasing difficulty; success on specific subsets of tasks directly correlates with Piaget's six stages (Wadsworth, 1984). Second, these subsets provide finer divisions of Piagetian stages and thus yield additional within-stage comparative data across species. Third, the tasks can be readily adapted for various species; most studies use either these tasks (e.g., Hallock \& Worobey, 1984; Redshaw, 1978; Wood et al., 1980) or closely related ones (e.g., Dumas \& Doré, 1989; Gagnon \& Doré, 1994). Thus, cross-species studies are not confounded by significant differences in experimental design (see footnote 1).

Details of Uzgiris and Hunt's (1975) tasks are provided for comparison with other studies (e.g., Antinucci et al., 1982; Gagnon \& Doré, 1994). Tasks are grouped according to the type of skill tested. We provide a descriptive label for each task for cross-reference with the Results section.

Visual pursuit. Tasks 1 and 2 respectively test the ability to visually follow a slowly moving and then disappearing object (Stage 2). The subject succeeds on Task 1 (arc track) if it tracks an object 
(determined by eye gaze, head position) smoothly through a complete arc. To succeed on Task 2 (object disappearance), a subject must remain gazing at the point of disappearance or return its glance to the starting point.

Simple visual displacements. Tasks 3 (partial hiding) and 4 (complete hiding) test Stages 3 and 4 , respectively: the ability to retrieve an object that is partly and then completely hidden under a single cover. In Task 3, the object may be obtained by pulling either the object or cover. In Task 4, a subject must remove the cover. Our Task 4, based on Uzgiris and Hunt's (1975) Task 4, corresponds to Gagnon and Doré's (1994) Stage 4b because Griffin was not allowed to search until the object was completely covered. We chose not to test Gagnon and Doré's Stage 4a (allowing search to begin during the covering process) to avoid overexposure and possible training of the task (see below). Task 5 (two sites, visible), which tests the beginning of Stage 5, involves two covers. The object is visibly bidden in the same place for two or more trials in a row before being hidden in the second location; the task tests whether a subject recognizes when the location has changed. Failure is common in young children and is called the "A-notB error" (see review in Diamond, 1990b). We used differently marked covers, as is often done for children (see Bremmer, 1978a, 1978b; Butterworth, Jarrett, \& Hicks, 1982; Diamond, 1990b; Goldfield \& Dickerson, 1981, although these studies differed somewhat from ours). Just as in some children's studies, we placed covers in front of Griffin and then hid the object. Use of marked covers and this hiding procedure may reduce the likelihood of A-not-B errors (Harris, 1973). We wished to see if a young parrot, like very young children, would make this error even under such circumstances. We used nuts for all trials to avoid possible perceptual complications. ${ }^{3}$

In Tasks 6 (two sites, alternating visible) and 7 (three sites, alternating visible), the hiding place varies respectively between two and among three covers. In both tasks, the subject must search only under the correct cover. We varied rewards or covers in successive trials.

Complex hidings. In Task 8 (three sites, successive visible) an object, in full view in the investigator's hand, is passed under successive covers until it is hidden in the designated site. The task tests the ability to follow an object's movement and search the location where it has most recently been seen. Success involves searching only the final location; searching in order of hiding is incorrect. Task 9 (superimposed covers) is the final test of Stage 5 competence. The subject must remove three superimposed covers to obtain the object. The test gauges a subject's persistence.

Invisible displacements. In Tasks 10-15, subjects cannot view a transfer but can only infer its occurrence. These tasks thus presumably require inferential, rather than perceptual, abilities. Successful completion indicates that subjects have achieved full Stage 6 object permanence (but see Doré et al., 1996).

Tasks 10-13 are similar to Tasks 4-7, except that the object is not in view during a transfer. The item is, instead, hidden in a small container or the experimenter's hand (the implementing cover); the subject sees the implementing cover, but not the item, move to one (Task 10,11) or a choice of two (Task 12) or three other covers (Task 13), and the experimenter surreptitiously transfers the object. Only then is the subject shown that the implementing cover is empty. To succeed, the subject must search directly under the correct screen. For reasons described below, we omitted Tasks 10-12.

Task 14 (successive invisible) repeats Task 8, but the object is not seen after it is initially placed in the implementing cover as the investigator moves between screens. To succeed, the subject may search either the last cover in the path or under all covers in order of hiding. To test whether the subject has simply formulated rules such as "go to last place the experimenter touched" or "go to last place object was seen," additional controls not in Uzgiris and Hunt's (1975) scale are used (de Blois \& Novak, 1994; Dumas \& Brunei, 1994). Here (Task 14a, controls) the experimenter places the item in the implementing 
cover, visits one screen, hides the object, shows the empty cover, visits another screen, and then leaves the implementing cover in an accessible site that varies for each trial. A third, untouched screen is a control to see if the subject examines only screens that were visited. A subject shows it is not using a "go to last place object was seen" rule by ignoring the implementing cover; a subject must also ignore the last place the experimenter touched to retrieve the item.

Task 15 is a trick: An object is hidden under an intermediate cover, but the investigator's hand continues to move under the other covers so that the subject is led to believe that the object is under the final cover. The task thus controls for possible inadvertent cues (see below).

Our Task 16 (substitution) is also a trick: The experimenter repeats Task 14 but surreptitiously hides an item less favored than the one that the subject initially observes. This task tests whether the subject has a representation of the hidden object and is not simply searching for something of interest.

For completeness, we also administered Task S, comparable to that of Sophian (1985) and Doré et al. (1996). Task S is a variant of the "shell game": An object is visibly hidden under one of three covers, and the experimenter then visibly exchanges the position of this cover with one of two others. Whether Task S should be the defining criterion for Stage 6 is unclear because it also tests attention, different types of memory, and spatial cognition (see Goulet, Doré, \& Lehotkay, 1996). The task nevertheless provides information about cognitive capacities.

Uzgiris and Hunt's (1975) tasks, although extremely valuable, may not be ideal. Researchers question (a) whether standardized tests that ignore environmental enrichment (enculturation; Bower, 1982; Flavell, 1985; Harris, 1983) can accurately pinpoint the age at which abilities emerge; (b) whether the tasks quantify the existent cognitive level of the subject or, instead, measure proficiency reached through training, learning, memory (Bjork \& Cummings, 1984; Dorf \& Dumas, 1987), or physical development (Baillargeon, 1987); and (c) the claim that success on the tasks demonstrates that subjects represent the hidden objects (see Pepperberg \& Funk, 1990). All these points merit scrutiny.

Enculturation may affect rate and extent of development. Such is likely for children (Bruner, 1964; Wishart \& Bower, 1985); chimpanzees (Pan troglodytes) given human-like experience outperform conspecificreared chimpanzees on imitation tasks (Tomasello, Savage-Rumbaugh, \& Kruger, 1993), and object permanence might be similarly affected. Thus, although the invariance of Uzgiris and Hunt's (1975) procedures ensures that enculturation implicit in a given task affects all species equally, studies generally do not examine effects of prior enculturation. We suggest that enculturation cannot facilitate performance beyond a species' inherent limits but can help it reach its maximum potential. Enculturation may not sufficiently facilitate optimal performance at a given age in a given species (see Macphail, 1987), but enculturation that facilitates eventual Stage 6 competence would seem a reasonable level under which to examine relative and absolute rates of development.

Success on specific Uzgiris and Hunt (1975) tasks may reflect training, learning, and memory (Dorf \& Dumas, 1987), whereas failure at a given age may reflect physical rather than cognitive limits (Baillargeon, 1986, 1987; Baillargeon, Spelke, \& Wasserman, 1985). We leave the first point for the Discussion. Very young subjects may fail early tasks merely because they physically cannot remove a cover (Doré \& Dumas, 1987; Flavell, 1985). Diamond (1990a, 1990b), however, has found that success on the later tasks (or stages) is likely independent of physical competence: Skills needed for later tasks seem related to maturation of specific brain areas involved in cognitive development. 
We agree that Uzgiris and Hunt's (1975) tasks do not test representational memory. For that reason, we added Task 16, on the basis of previous work with nonhuman primates (Tinklepaugh,1928, 1932). The task specifically tests whether grey parrots have a representation of the hidden item.

\section{Procedure}

At least two persons administered trials. Experimenter 1 sat behind the apparatus and manipulated the objects. Experimenter 2 sat behind the parrot; he or she occasionally restrained Griffin by placing his or her hands around the bird's body but did not remove the bird from the towel on which the bird and the humans sat. After Experimenter 2 released the bird, he or she and Experimenter 1 and, on early tasks, a third person observed Griffin's behavior; one of these observers recorded the session's events in a notebook. Several different humans were involved, and all humans present during the experiment took all roles (hiding objects, observing actions, and scoring results). Such role transfer helped ensure that Griffin did not become adept at reading possible cues presented by a single individual.

We omitted Tasks 10-12 to see if Griffin could succeed on a complex invisible displacement without experiencing simpler ones. Although mammalian object permanence apparently develops in a fixed sequence (Doré \& Dumas, 1987; Dumas \& Doré, 1989), such may not be true for birds. We also believed that, on occasion, a shift to a more challenging task helped focus Griffin's attention. This shift also showed that Griffin was not being trained in a stepwise manner, because success at a more complex task was then independent of experience with simpler tasks (see Discussion).

Griffin worked only for short periods. Sessions normally were 15-30 min and consisted of two or three tasks, beginning with repetition of the last task from the previous session. The repetition tested Griffin's willingness to work: Failure to repeat an earlier task usually indicated motivational problems and separated such problems from an inability to perform a task. To maintain his motivation, we varied objects or foods between trials (except for task 5) and allowed him to eat the food or play with the toy he had found (Doré \& Dumas, 1987). Even with this protocol, Griffin generally became uncooperative after about 20 min. Thus, although we had planned never to end a session until we had reached a task beyond his current level of competence, he often lost interest in sessions before that point.

Griffin was tested weekly until he succeeded on Task 15. We could thereby track development in a finegrained manner without providing excessive opportunities for learning the tasks (de Blois \& Novak, 1994). Because Griffin had to have a stable hierarchy of object or food preferences for Task 16, we postponed testing that task until he was 33 weeks old. We also administered the test to Alex.

We performed Tasks 14a and S when Griffin was 51-52 weeks old and simultaneously with Alex. These trials thus lacked developmental relevance, but the hiatus lessened the likelihood of habituation or training effects and the data could still substantiate our claims for Stage 6 competence.

\section{Procedural Difficulties}

Experimenter cueing. Uzgiris and Hunt's (1975) procedures, which involve face-to-face interaction between subject and experimenters, might cue a subject via an experimenter's direction of gaze or face and body posture (Gardner \& Gardner, 1975; Wood et al., 1980). Some researchers (e.g., Gagnon \& Doré,1992,1994; Pepperberg \& Kozak, 1986; Triana \& Pasnak, 1981; Wood et al., 1980) reject the influence of such cueing for three reasons. First, far more direct cues are inherent in the visible displacements. Second, even obvious pointing to the correct cover does not help subjects that do not understand the task or the indicative nature of pointing, or, alternatively, are unmotivated (see Pepperberg \& Kozak, 1986; Triana \& Pasnak, 1981). Note, too, that Griffin never appeared to wait for reactions of the experimenters before or during his actions. Finally, successful completion of Task 15 , 
which tests whether the subject will go directly to where the experimenter knows the object exists, argues against cueing. ${ }^{4}$ As a final control, however, we administered Task 15 trials in which the experimenters wore mirrored sunglasses. These trials (Task 15a) were run with Alex and Griffin several months after the completion of the original series; such a delay helped to avoid habituation and lessened the possibility of memory for the task.

Odor cues. Experimenter-based cueing is not the only possible confound: Many tasks use foods, and thus odor cues might influence the outcome. For four reasons, we do not believe that odor cues affected our results. First, although olfactory sensitivity in birds is not well documented (Stettner \& Matyniak, 1968) and the relative importance of this sense appears to vary across avian species (Harriman \& Berger, 1986; Macphail, 1982; Wenzel, 1967), Gagnon and Doré (1992) argued that odor cues are unimportant even for animals such as dogs that are known for olfactory sensitivity. Second, data from previous work with grey parrots (Pepperberg \& Funk, 1990; Pepperberg \& Kozak, 1986) suggest that odor is unlikely to be an important factor in these birds' searches: Birds made similar numbers of mistakes regardless of whether the hidden object was food or nonfood. Sometimes birds would eat little of the food rewards. Third, the nuts or seeds used as food rewards are not heavily scented, and these were covered by screens that had at some time contained food or by pieces of human-handled paper that were also somewhat odorous. Additional olfactory distractors were crumbs remaining from previous trials or play sessions with different foods. Fourth, Task 15 specifically tests for odor cues because the object is left under one screen, but the investigator gives the appearance of placing the object elsewhere. An animal using odor cues would not be fooled by this procedure.

\section{Scoring Criteria}

Performance criteria were similar to those used in previous studies with Uzgiris and Hunt's (1975) tasks (Pepperberg \& Funk, 1990; Pepperberg \& Kozak, 1986; Wood et al., 1980). A trial was considered correct if Griffin uncovered the hidden item or performed another acceptable action within 1-2 min of the hiding. For each task, Uzgiris and Hunt listed 3-5 alternative erroneous actions, such as pulling off the wrong cover, losing interest in the object, or doing a haphazard search; Griffin was scored accordingly. Correct searches must be done consecutively multiple times for each task. If Griffin was correct on successive trials after erring midway through a session, however, we occasionally proceeded to the next task. We recorded mistrials when Griffin (a) removed and immediately manipulated covers without searching for the hidden object (i.e., ignored the actual task) ${ }^{5}$ or (b) interfered with the placement of the object.

\section{Results}

Table 1 shows the results of the trials and the age at which Griffin succeeded on specific tasks. The tasks are grouped into series, following the procedures of Uzgiris and Hunt (1975) and Wood et al. (1980). We provide details of the trials based on notes taken during sessions.

\section{Visual Pursuit}

Task 1 (arc). On his first session, when he was 8 weeks old, Griffin tracked (by moving his head) a slowly moving object. He completed three trials: He followed an orange plastic ring, a small rawhide bone, and a red plastic bottle cap. Unlike the adult subject in a previous experiment (Pepperberg \& Kozak, 1986), he did not attempt to grab these objects while they were in motion.

Task 2 (object disappearance). In this task, which involves tracking an object that briefly disappears from view, Griffin also succeeded at 8 weeks. He lowered and tilted his head while searching for a red bottle cap and a rawhide bone. Because he did not follow the orange plastic ring that he had followed earlier, 
we switched objects. He then tracked a pen cap and the bottle cap once again. We thus believed that failure to track the ring was based on motivation and considered Griffin to have passed this stage.

Table 1. Results of the Trials and the Age at Which Griffin Succeeded in a Given Task

\begin{tabular}{|c|c|c|c|}
\hline Task & Stage & Response and order of actions & $\begin{array}{c}\text { Age } \\
\text { (Weeks) }\end{array}$ \\
\hline \multicolumn{4}{|c|}{ Visual pursuit of slowly moving objects } \\
\hline 1 & 2 & Follows object through arc 3 times in succession & $\leq 8$ \\
\hline 2 & 2 & Follows object to disappearance twice, then fails, follows 2 times more & $\leq 8$ \\
\hline \multicolumn{4}{|c|}{ Search for simply hidden objects } \\
\hline 3 & 3 & $\begin{array}{l}\text { Objects partially hidden: Plays with cover, succeeds by chance, ignores trial } \\
\text { Obtains partially hidden object } 3 \text { times in succession }\end{array}$ & $\begin{array}{l}8 \\
9\end{array}$ \\
\hline 4 & 4 & $\begin{array}{l}\text { Scratches near fully hidden object, reacts to loss } 2 \text { times, succeeds by chance once } \\
\text { Reacts to loss } 2 \text { times, succeeds by chance once } \\
\text { Scratches near object } 2 \text { times, succeeds by chance once } \\
\text { Reacts to loss, fails in his attempt to recover object } \\
\text { Ignores first two trials, reacts to loss } 2 \text { times } \\
\text { Succeeds by chance } 2 \text { times, then succeeds after deliberate action } \\
\text { Removes cover to obtain object } 3 \text { times in succession } \\
\text { Removes cover to obtain object } 3 \text { times in succession }\end{array}$ & $\begin{array}{l}9 \\
10 \\
11 \\
12 \\
13 \\
14 \\
15 \\
16\end{array}$ \\
\hline 5 & 5 & $\begin{array}{l}\text { Choice of two sites: Fails } 1 \text { time, succeeds } 1 \text { time, fails } 2 \text { times, succeeds } 1 \text { time } \\
\text { Succeeds } 5 \text { times in succession }\end{array}$ & $\begin{array}{l}17 \\
18\end{array}$ \\
\hline 6 & 5 & Choice of two alternating sites: Succeeds 3 times in succession & 18 \\
\hline 7 & 5 & $\begin{array}{l}\text { Three alternating sites: Haphazard search, mistrial, succeeds } 1 \text { time, ignores next trials } \\
\text { Succeeds } 1 \text { time, fails } 1 \text { time, succeeds } 1 \text { time, fails } 2 \text { times, succeeds } 3 \text { times in succession }\end{array}$ & $\begin{array}{l}19 \\
20\end{array}$ \\
\hline \multicolumn{4}{|c|}{ Search following more complex hidings } \\
\hline 8 & 5 & $\begin{array}{l}\text { Successive } 3 \text { sites: Search with respect to hiding order, succeeds } 2 \text { times, search with } \\
\text { respect to hiding order, succeeds } 1 \text { time }\end{array}$ & 20 \\
\hline 9 & 5 & Superimposed covers: Succeeds 3 times in succession & 20 \\
\hline \multicolumn{4}{|c|}{ Invisible displacements } \\
\hline 13 & 6 & Three sites: Searches implementing cover 1 time, succeeds 3 times in succession & 21 \\
\hline 14 & 6 & $\begin{array}{l}\text { Successive } 3 \text { sites: Succeeds } 2 \text { times, fails } 1 \text { time, mistrial, succeeds } 2 \text { times } \\
\text { Succeeds } 5 \text { times in succession; final search is with respect to hiding order }\end{array}$ & $\begin{array}{l}21 \\
22\end{array}$ \\
\hline $14 \mathrm{a}$ & 6 & Control trials: Succeeds 2 times with 2 sites, succeeds 3 times with 3 sites & 51 \\
\hline 15 & 6 & $\begin{array}{l}\text { Trick: Succeeds but skips a box } \\
\text { Stops looking after last screen, succeeds } 2 \text { times }\end{array}$ & $\begin{array}{l}21 \\
22\end{array}$ \\
\hline $15 \mathrm{a}$ & 6 & Repetition with blindfolded experimenters: Succeeds 2 times & 51 \\
\hline 16 & 6 & Substitution trial: Succeeds 2 times & 33 \\
\hline $\mathrm{S}$ & 6 & "Shell game": Succeeds 2 times, errs, succeeds 3 times, including sham trial & 52 \\
\hline
\end{tabular}




\section{Simple Visual Displacements}

Task 3 (partial hiding). When required to retrieve a partially occluded object, Griffin seemed to fail in his 8th week. We partially covered a red bottle cap with a piece of paper; he pulled at and played with the paper. In a second trial with paper and the same cap, he stumbled onto the paper and thus unearthed the cap; his actions did not seem deliberate. We next used a pen cap; he did not seem to follow our actions. Whether failure was due to his short attention span or an inability to perform the actions was unclear. Griffin succeeded when he was 9 weeks old. He uncovered a green bead, a blue plastic ring, and a green plastic ring from under paper covers. He showed no hesitation.

Task 4 (complete hiding). When presented with a completely covered object, Griffin, at 9 weeks, reacted to the loss. He once walked to and scratched around paper covering a nut and twice exhibited displacement scratching as soon as we covered the targeted object (an almond, a wooden ball) with paper. He did extract a green ring from under paper at 9 weeks, but his actions did not appear intentional-he scratched around the paper, noticed something underneath, and pulled at the item. In the 10th week, he reacted to the loss of a pen cap and a wooden ball but did not remove the paper covers. On the third trial, he ran to the box used as a cover and played with it; when it tipped, he noticed and ate the nuts that were then exposed. In the 11th week, after failing to obtain a nut and a pen cap, his scratching around a paper towel eventually uncovered a hidden bead on the third trial, but his behavior appeared to be more displacement than deliberate. From Week 11 onward, he would accidentally uncover objects while "helicoptering" in practice flight and then interact with the uncovered item. At 12 weeks he twice ran to the experimenter who had hidden the pen cap and emitted begging cries. ${ }^{6} \mathrm{He}$ also made his first deliberate attempt to remove a paper cover from a watch band but was unsuccessful. In the 13th week, Griffin ignored die task (preened) on trials with a pen cap and plastic keychain; he subsequently reacted to two additional trials with the pen cap by scratching, ruffling, and screeching, but he did not remove the boxes used as covers. Note that between the 11th and 13th week, he fledged: He began to "helicopter" several inches above the floor and spent most of his time practicing. At Week 14 he used this action to remove a paper screen from a pen cap and then a toy cup. In the third trial, however, he deliberately pulled a pen cap out from under the paper towel used as the cover. In his 15th week, he succeeded on three trials by removing paper towels to obtain seeds, a pen cap, and seeds. In all trials, size, shape, and sometimes color of the paper covers differed. He repeated his success at 16 weeks with small boxes whose taped edges he could easily grasp: In three trials he obtained a pen cap and seeds.

Task 5 (two sites, visible). We tested Griffin at Weeks 17 and 18 with two differently marked white plastic boxes of the same type used in Task 4. We alternated location of the hidden food across trials, consistent with demands of the task. At Week 17, he found the nut under the correct box the first time it was hidden (at $A$ ) and again when it was hidden under the same box in the same location (these base-line trials are not noted in Table 1). ${ }^{7}$ On his next trial, he went to the same box in the same location, A, where the nut previously was hidden, rather than to the correct location, B (i.e., he made the A-not-B error). He was correct on the next trial (obtained a nut in $B$ ), made the A-not-B error on the succeeding two trials (persevered twice at B when the nut was now in A), and was correct on the last trial for the week (went to A). Errors were made despite the differently marked boxes; possibly he did not notice the colored Xs on their tops. At Week 18, he was correct on five trials (plus appropriate baseline trials).

Task 6 (two sites, alternating visible). At Week 18, Griffin correctly performed three trials in succession. We used cups that varied in color and size between trials. On the first trial, he lifted the cup to obtain a wooden bead; on the second, he lifted the other cup to obtain a seed; and on the third trial, he lifted the first cup to obtain a pen cap. 
Task 7 (three sites, alternating visible). Griffin did not succeed at Week 19. On the first trial, he searched haphazardly. The second trial was a mistrial: He grabbed a cover and played with it. He succeeded on the third trial, but in successive trials he ignored the barrels and ran to the experimenters and tried to climb onto their legs or laps. At Week 20, he succeeded. He found the seed on the first trial, looked under the previously correct box in the next trial (i.e., failed to find the seed), succeeded in obtaining a pen cap in the third trial, looked under a previously correct cover in the fourth (seed) and fifth (pen cap) trials, and then succeeded in obtaining a nut, bead, and ring, respectively, in the sixth, seventh, and eighth trials. (As before, we changed color and sometimes box size between trials in this and all following tasks.)

\section{Successive Visible Displacements}

Task 8 (three sites, successive visible). Griffin also succeeded at Task 8 in Week 20; he responded correctly on 3 of 5 trials, although not consecutively. On his first (nut) trial, he searched in order of hiding (i.e., failed), but he correctly searched under the last box on the next two trials for, respectively, a pen cap and a nut. On his fourth trial, he again searched in the order of hiding, but he successfully recovered a seed (went to last box) on his fifth trial. He never searched haphazardly nor where the object had previously been found.

Task 9 (superimposed covers). When we began to collect screens for this task (immediately after Task 8), Griffin ran to the experimenters for attention. To see if he could nevertheless perform this task while still in Week 20, we tested him after a 2-day pause. He succeeded at once, removing nested barrels and then nested boxes to obtain a bead and then a seed.

\section{Invisible Displacements}

Task 13 (three sites, invisible). Given Griffin's progress at 20 weeks, we decided to see how he would perform if we skipped Tasks 10-12. At 21 weeks, Griffin was more interested in exploring his room and interacting with humans than working on the tasks; we felt that moving ahead might maintain his interest. On Trial 1, he checked the small box used for the invisible displacement and then searched directly under the correct box to obtain a nut. He searched directly on his next three trials to obtain first a pen cap, then nuts.

Task 14 (three sites, successive invisible). Because Griffin succeeded on Task 13, we proceeded to Task 14 at Week 21, without returning to Tasks 10-12. On the first two trials, Griffin searched the last of the three screens and found a pen cap and a nut. On the next trial (hidden nut), he searched the first and second screen and then began to preen. On the fourth trial, he skipped the first screen, searched the second and third in order, and found the bead. He preened during the next trial (i.e., did not watch the experimenters); after a break, he searched the last screen on the final two trials to obtain nuts. At Week 22 , he succeeded on five trials in a row; in his last trial he searched in order of hiding. These trials all used seeds or nuts.

Task 15 (trick). Four consecutive successes on Task 14 are required for proceeding to Task 15, but because Griffin had succeeded in five of seven trials at 21 weeks, we decided to proceed to Task 15 in that session. In Trial 1 he searched the last screen and then the first, skipping the second, which held the nut. At 22 weeks, after completing Task 14, he stopped after searching only the last screen on Trial 1 but performed appropriately on his second two trials (i.e., searched backward from the last screen until the object was found).

Task 16 (substitution). On his first trial (at 33 weeks), we showed Griffin a cashew (a favored item) and then hid a Harrison's Bird Diet nugget (a less favored food) during a successive invisible displacement. Griffin went to the final box, turned it over, and looked at the pelleted food. He immediately went to the 
other boxes, turned them over, and then ran to the experimenters. He reacted the same way when we repeated the trial with a different box as the final hiding place. We replicated the procedure with a true hiding; Griffin uncovered and ate the cashew and did not continue his search.

We also administered the test to Alex. Because he had not had such tasks in several years, we first administered Task 14; be promptly uncovered the hidden cashew from the last cover. We then administered Task 16: After removing the cover and finding a food pellet, he turned away from the apparatus and to the experimenters. He narrowed his eyes to slits, which we have come to interpret as anger. ${ }^{8}$ To ensure his cooperation on the next trial, we gave him the cashew he had expected. His reaction after uncovering the pellet on the second test trial was similar to his reaction on the first, except that he banged his beak on the table, which is also a sign of frustration or displeasure.

Task 14a (control). Trials were performed when Griffin was 51 weeks and were replicated with Alex. We used three blue plastic cups as screens and a blue bottle cap as the implementing cover so that color would not be a cue; we used hidings described by Dumas and Brunei (1994). We used right, left, and middle cups as hiding places, in that order, visited two of the three cups in each task (i.e., one cup was a control), showed the empty cap after the hiding, and placed the implementing cover alternately between the middle and side cup or after a side cup. Griffin and Alex again immediately went to the correct cup on all trials. They never searched the implementing container or the wrong cup.

Task 15a (sunglass control). We also gave Alex and Griffin Task 15 trials in which experimenters wore mirrored sunglasses. Griffin, even after a hiatus of 29 weeks, performed appropriately on two trials separated by several hours. The direction of hiding differed between trials. Alex also searched appropriately on the first trial. On the second trial, however, he used his beak to knock all the barrels toward the edge of the table on which the trials were held. We did not attempt a retrial.

Task S (shell game). We hid a nut under the middle cover and transposed it with the left; under the middle cover and transposed it with the right; under the left cover and transposed it with the middle; under the right cover and transposed it with the left; and under the right cover and transposed it with the middle; we also put a nut in the middle cover and transposed the right and left ones. Griffin, at 52 weeks, succeeded on all but the third task, when he went to the left cover. He never hesitated and seemed to track the experimenter's hand very closely. Alex was correct on every set of trials. On two trials, however, we hid a cork rather than a nut; he asked for a nut ("Wanna nut") after finding the cork.

\section{Discussion}

Previous studies have demonstrated psittacine Stage 6 competence on standard Uzgiris and Hunt (1975) tasks (Funk, 1996; Pepperberg \& Funk, 1990; Pepperberg \& Kozak, 1986), but only Funk's study on kakarikis (Cyanoramphus auriceps) was longitudinal and also tested for the subjects' representation of the hidden item. We have described how at least one grey parrot developed and performed on representational and additional Stage 6-type tests, and thus we have provided preliminary data for crossspecies comparisons. How grey parrots develop in the wild is unknown; we thus cannot correlate Piagetian stages and natural behavior. We can relate our data to two milestones in captivity, fledging and weaning. We also discuss environmental effects (including possible training and learning) and the implications of having a concept of object permanence. The extent to which object permanence reflects behavioral and cognitive capacities has been discussed previously (Pepperberg \& Funk, 1990).

\section{Development of Object Permanence and Comparisons With Other Species}

The age at which object permanence develops varies with species (see Gagnon \& Dorf, 1994); such variation may reflect different physical or cognitive maturation. Griffin, for example, developed rapidly 
compared with primates and overall more rapidly than dogs or cats. He temporarily plateaued at a different stage and time than nonparrot species; like great apes and kakarikis but unlike dogs or cats, he made A-not-B errors. He may not be a representative grey parrot, but these differences may also be related to psittacine ecological or developmental constraints and environmental enrichment.

Differences in ontogenetic progress and behavioral milestones. If Griffin is not atypical, grey parrots progress differently from mammals. Great apes generally reach the earliest stages more rapidly than humans (e.g., Stage 3 by about 4 months), plateau temporarily at Stage 5, and reach Stage 6 about the same time as humans (Mathieu \& Bergeron, 1981; Redshaw, 1978; see Gagnon \& Doré, 1994). Monkeys develop more quickly than apes but slow as tasks increase in difficulty and fail to reach Stage 6 (de Blois \& Novak, 1994; Poti, 1989; Spinozzi, 1989; see Gagnon \& Doré, 1994). Cats and dogs develop more rapidly still, reaching Stage 5 in a 4-week period ending at 7-8 weeks (Dumas \& Doré, 1989; Gagnon \& Doré, 1994). Cats develop no further; dogs master standard invisible displacements after several additional months (Gagnon \& Doré, 1994) but fail Task S (Doré et al., 1996). Griffin, in contrast, plateaued between Stages 3 and 4 (weeks 9-14) and completed standard Stage 5 and 6 tasks by 22 weeks, an age comparable to kakarikis (Funk, 1996); he succeeded on additional Stage 6 tasks, including Task S, at 51-52 weeks. Interestingly, parent- but not hand-reared kakarikis also plateau, and at Stage 4, but not for as long as Griffin (Funk, 1996).

Why Griffin failed Stage 4 until Week 15 is unclear. He reacted to object loss at Week 9, which suggests Stage 4 competence (Piaget, 1936/1952), but could not obtain the object Possibly, he could have succeeded had our task not required that he physically remove a cover (Dumas \& Doré, 1989). Also, his plateau coincided with development of flight and may have been a consequence of codevelopment or how he apportioned his attention. Whether flight and Stage 4 develop simultaneously in other grey parrots, in nature as well as in the laboratory, and the possible importance of such codevelopment (e.g., memory for a nest hole no longer in view or a predator that "disappears" into a tree), remain unknown. Griffin may have been more interested in practicing flight than the tasks, but neurological establishment of flight connections may also have precluded concurrent development of connections needed for Stage 4 (cf. Rakic, Bourgeois, Zecevic, Eckenhoff, \& Goldman-Rakic, 1986).

Interestingly, temporary plateaus in other species may co-occur with developmental milestones. For dogs, Stage 5 plateaus occur at weaning (Gagnon \& Doré, 1994); for children, final stages of object permanence emerge as words involving movement and disappearance are acquired (see Meltzoff, 1988; Tomasello \& Farrar, 1984,1986). Although flight in kakarikis develops between Stages 2 and 3, weaning occurs just before Stage 4, and emerging social behavior might play the same role as did flight for Griffin (M. S. Funk, personal communication, April-May, 1996). Investigating correlations between the emergence of object permanence and natural behavioral patterns in different species might provide important data. We do not know what happens to wild grey parrots at 22 weeks, when Griffin succeeded at standard invisible displacements. In the laboratory, he was not entirely weaned, and flight had developed several weeks earlier.

We learned from breeders that Stage 2 emerges early in grey parrots (K. Carleson, T. Clyne, R. Lawson, and C. Parks, personal communications, January-March, 1996). Nestlings follow feeding syringes at 2-3 weeks, essentially as soon as their eyes open. By 18 days, they follow syringes through a $180^{\circ}$ arc; by 20 days, they track until a syringe goes out of sight and cheep as soon as it disappears ( $T$. Clyne, personal communication, March 1996) Unlike mammals, who search for a relatively stable teat (possibly using smell) and who need not necessarily vie with litter mates for nourishment, parrots must compete with nest mates for access to a single source of food by tracking a parent's beak. The earlier such tracking capacity develops, the more likely is survival. Such tracking, interestingly, develops later in kakarikis than in grey parrots (Funk, 1996). 
A-not-B error. Why do A-not-B errors exist in primates and parrots and not in dogs or cats? Explication likely depends on determining the error's underlying cause. At least four possibilities exist. First, a child's A-not-B errors may be related to memory (Bjork \& Cummings, 1984; Diamond, 1990b). The child seems not to store information from the second hiding (see Flavell, 1985) or cannot inhibit responding based on previous association of location and reward (Diamond, 1990a). Second, the error may involve coordinating position of objects to the self, rather than processing allocentric spatial cues (egocentricity, Bremmer, 1978a, 1978b); that is, it may involve reliance on previous associations-"choose to my right"-rather than current input about the entire situation. Subjects that rely on external reference from a very early age thus might not exhibit the error (Gagnon \& Dor6, 1994). Third, the error may indicate incomplete comprehension of object permanence (Piaget, 1936/1952, 1937/1954): The object is seen as an integral part of the hiding place rather than as having an independent existence. Finally, the error may involve an incompletely developed ability to process spatiotemporal information, that is, to understand object movement (Wellman, Cross, \& Bartsch, 1986).

These proposals do not seem to explain why dogs and cats, but not parrots and primates, avoid A-not-B errors. Memory would seem relevant for any subject: Children, for example, err less if memory load is reduced, that is, if they can search immediately after the object is hidden in the second location (see Diamond, 1990b), if cover discriminability is increased, or if cover removal is simplified. Moreover, if given more than two choices of cover, children's errors are not all to the previous location but may cluster near the correct choice (Bjork \& Cummings, 1984; but see Diamond, 1990b). It seems unlikely that dogs and cats have better memories for alternating specific locations than other species during infancy. Nor do we believe that dogs and cats are less likely to form egocentric associations than other species in infancy, or that they are inherently better at understanding the separation between object and cover, or at processing spatiotemporal information to the extent that this error would not exist: In children and monkeys, A-not-B errors appear to be associated with incomplete maturation of brain areas related to memory and to inhibition of neonatal reflexes (respectively, the dorsolateral prefrontal cortex and supplementary motor area of the frontal cortex; Diamond, 1990a, 1990b). Specifically, although dogs and cats, and even more so birds, do not likely have brain structures identical to those described in primates as requiring maturation to overcome the A-not-B error, we would be surprised to find analogous brain areas in birds and not find such areas (or homologous ones) in dogs and cats. Might the error indeed occur in dogs and cats but for only a very brief period that reflects their overall compression of stages? Griffin erred in only one session. Because of individual developmental differences, the error might be missed if the same dogs and cats are not tracked over time.

Additional Stage 6 tasks. Doré et al. (1996) suggested that Uzgiris and Hunt's (1975) invisible displacements do not adequately test Stage 6 competence. They proposed instead a "shell game" (see Sophian, 1985), which tests attention, working memory, and spatiotemporal cognition. Whether Stage 6 competence ought to be redefined in this manner is unclear, but we performed such tests for completeness. ${ }^{9}$ Both Griffin and Alex passed, which suggests that grey parrots, unlike dogs and cats but like humans and great apes, develop a robust sense of object permanence.

\section{Environmental Influences}

Effects of training and learning. In developmental studies, evaluation procedures may teach as well as test a targeted concept (Chapman, 1987; Cornell, 1978; Hediger, 1981; Thomas \& Walden, 1985). Conceivably (see Pepperberg \& Funk, 1990), subjects could (a) learn a task from observing experimenters' behavior, (b) use repetitions and even mistrials for trial-and-error learning of each task (Doré \& Dumas, 1987), or (c) use tasks as a stepwise means to learn a concept. For the following four reasons, we believe that we did not teach any concepts, that Griffin did not learn from the procedures, 
and that he did not acquire simple rules that facilitate success at Stage 6 tasks without object permanence (Gagnon \& Doré, 1992).

First, we never demonstrated a correct response (see Pepperberg \& Funk, 1990; Pepperberg \& Kozak, 1986). If Griffin did not respond within the allotted time, a cover was not-as in Uzgiris and Hunt's (1966) or Sophian's (1985) studies-lifted in his presence; cover and object were removed together. Moreover, different items or covers were generally used in successive trials to prevent any association between objects and covers.

Second, we cannot rule out one-trial learning of individual tasks, but Griffin's data were generally inconsistent with trial-and-error learning. Had learning occurred, he would have consistently improved during a task; in fact, he sometimes erred after correct trials (e.g., Week 20 on Tasks 7 and 8). Note that he sometimes failed on successive attempts in a given week but succeeded immediately the next week with no intervening practice (e.g., Weeks 17 and 18 on Task 5) ${ }^{10,11}$ Because he skipped Tasks 10-12, Task 13 was his first invisible displacement; success on his first trials thus could not have been a consequence of learning about such displacements. Learning may, however, have played a role in Task 4 if codevelopment of flight was not a factor in his plateau.

Third, if tasks provide a stepwise means of learning, success on one task should facilitate success on subsequent tasks. Such was not the case. After finishing Task 4, for example, Griffin immediately made the A-not-B error on Task 5 but succeeded on all trials the first time he was given Task 9 , which is unique. Most important, however, is that presentation of and success on visible displacements need not facilitate success on invisible ones (e.g., see results with rhesus monkeys; de Blois \& Novak, 1994). Specifically, if visible displacements enable subjects to devise rules such as "go to last place you saw the container" or "go to last place the experimenter touched" (Gagnon \& Doré, 1992), monkeys (and presumably cats; Dumas \& Doré, 1989) either cannot devise such rules or cannot transfer such rules to a new situation. Learning and training apparently enable a subject to proceed only as far as its species capacities allow. ${ }^{12}$

Fourth, Griffin's data were not consistent with simple rule-governed behavior. If he used the rule "search last place you saw object," he would, on Trial 1 of Task 13, have quit after seeing that the implementing container was empty. If he used "search screen in most recent contact with container," he would have made no intermediate or sequential searches in Task 14 after successfully going to the final screen in the first two trials. Moreover, during postexperiment control trials (29 weeks after the end of formal testing), Griffin and Alex searched neither the last place the object was observed (implementing container) nor the screen last touched by experimenter or container; both removed the cover that actually hid the object. Finally, they did not "follow eye gaze" (de Blois \& Novak, 1994): Task 15 results did not differ when researchers wore mirrored sunglasses.

General enrichment. Griffin's play sessions likely provided enculturation. He did not practice uncovering items, but he did learn to chew, toss, or throw items subsequently hidden or used as covers, and he interacted with multiple items simultaneously. Such opportunities may have advanced his physical ability or dexterity to a level beyond that of a bird lacking such experience. Enculturation did give Griffin an advantage in Task 5: Alex, who had no opportunity to interact with multiple separate items before being tested on Task 5, succeeded only after he received such exposure (Pepperberg \& Kozak, 1986). Enculturation also likely prevented test trials from being aversive (Pepperberg \& Funk, 1990). How Griffin's concurrent mirror exposure might have improved his performance is unclear. ${ }^{13}$ 
Does success on object permanence tasks indicate general cognitive capacities? We concentrate on the claim that object permanence implies representational ability. For Piaget (1936/1952, 1937/1954), subjects that succeed on Stage 6 not only mentally represent invisible transfer of an object but also encode its specific attributes (note Flavell, 1985); that is, they have full representational capacities. Uzgiris and Hunt's (1975) tasks, however, demonstrate merely that a subject searches for something of interest. Only if subjects react with surprise or displeasure (admittedly subjective criteria) or continue to search when the purportedly hidden item is replaced by one less favorable (Tinklepaugh, 1928,1932) can researchers assume that specific attributes of a hidden item have been encoded (see Flavell, 1985; LeCompte \& Gratch, 1972; Pepperberg \& Funk, 1990). To uphold Piaget's claim, Stage 6 criteria should include Task 16. ${ }^{14}$ Griffin's and Alex's behavior on Task 16 suggest that they did conceptualize what was hidden: Griffin continued to search, and Alex displayed displeasure at what he found.

In sum, ontogenetic comparisons based on a Piagetian framework may have limitations (e.g., Bower, 1982), but this framework offers pertinent comparative guidelines for examining the strategies and underlying mechanisms that various species use to solve common problems. Few other systems enable valid comparisons to be made among primates, nonprimate mammals, and birds. We reaffirm, as proposed previously (Gagnon \& Dor6, 1994; Parker, 1990; Pepperberg \& Funk, 1990) that the study of object permanence has not only already demonstrated intriguing parallel development in several evolutionary lines, but may also, if extended to comparisons between closely related species, reveal important differences about cognitive, neurobiological, and evolutionary traits.

\section{NOTES}

${ }^{1}$ According to Baillargeon (e.g., Baillargeon, 1986, 1987; Baillargeon \& DeVos, 1991; Baillargeon, Spelke, \&. Wasserman, 1985), a subject ostensibly in Stage 1 will demonstrate some understanding that objects exist when occluded if the test paradigm does not require an active search for the hidden object. The habituation paradigm used by these researchers, however, is difficult to apply with appropriate controls to animal studies. We therefore make our comparisons to standard Piagetian stages.

${ }^{2}$ Wise et al. (1974) reported Stage 6 object permanence for rhesus monkeys (Macaco mulatto), but Doré and Dumas (1987) argued that the procedures used may invalidate the conclusions on the rate and level of object permanence attained. Dogs achieve Stage 6 according to standard invisible displacement tests (Gagnon \& Doré, 1993, 1994) but fail (Doré et al., 19\%) when the task is a variant of the "shell game" (Sophian, 1985). Whether the shell game should be the defining criterion for Stage 6 is unclear because it tests different types of memory, attention, and spatial cognition than are tested by standard invisible displacements (Goulet, Doré, \& Lehotkay, 1996). And, although Gagnon and Doré (1992) questioned whether parrots do achieve Stage 6, psittacids have succeeded on standard invisible displacement tasks (Funk, 1996; Pepperberg \& Funk, 1990; Pepperberg \& Korak, 1986), and this study provides further evidence for such behavior.

${ }^{3}$ Butterworth et al. (1982) suggested that if the object is changed, the subject may not recognize that the set of trials in the second location is related to the first set of trials.

${ }^{4}$ One might argue that the experimenter unconsciously looks at the place she or he expects the subject to choose (the "logical" hiding place), even though body and head position are being controlled. Note, however, that the screens are separated by only about $3.5 \mathrm{~cm}$ and that the experimenter's eyes are 80-90 $\mathrm{cm}$ from the objects; such distances make eye orientation an unlikely cue (Miller \& Murphy, 1964). 
${ }^{5}$ We recorded mistrials when Griffin was clearly fixated by the covers. Even if an object was uncovered in such a trial, Griffin appeared oblivious to the item and focused his entire attention on the covers; he continued to manipulate the covers until we removed them from his beak or feet. Such behavior contrasted with that in Task 4, for example, when he would interact with an object that he uncovered by accident.

${ }^{6}$ Because two experimenters were present, such behavior suggested that he might be looking toward the agent of hiding and thus that he comprehended some limited object-agent relations. Such a possibility needs further investigation.

${ }^{7}$ Baseline trials are necessary for Task 5 to test for the A-not-B error: To learn whether the subject continues to search in the previously correct location even though she or he is shown that the location of the hidden object now differs, the subject needs to have experience with the object being hidden hi the same place (same cover, same location) two or more times in a row.

${ }^{8}$ Although we do not intend to anthropomorphize Alex's behavior, we have learned that the slit-eye look is usually a prelude to our being bitten if we continue the actions that have caused Alex to adopt this pose. We are in similar danger of being bitten if we ignore Alex's beak-banging behavior.

${ }^{9}$ We did not administer all the tests described by Doré et al. (1996) because our subjects succeeded on the most difficult ones.

${ }^{10}$ Conceivably, Griffin's behavior could reflect insight learning (e.g., Kohler, 1927/1976) but such a process is, by definition, different from trial-and-error learning. In an ontogenetic study, moreover, such behavior is most likely to reflect developmental maturation.

${ }^{11}$ Chapman's (1987) research with children also provides weak evidence that increased task exposure does not improve performance: He divided subjects in his longitudinal study into Groups 1 and 2; the former had roughly twice the number of tests as did the latter. The former group scored slightly better than the latter during the course of the experiment, but the difference in scores was not significant.

12 Conceivably, even if purported success on invisible displacements in some laboratories was not a consequence of comprehending object permanence but of learning these rules, such success still demonstrates an advanced level of cognitive processing unavailable to animals that fail such tasks.

${ }^{13}$ Although mirror exposure might aid the development of general spatial awareness, Griffin did not have an opportunity to practice any specific spatial skills: Unlike subjects in a previous mirror study (Pepperberg, Garcia, Jackson, \& Marconi, 1995), he was not asked to find an object based on its reflection; thus, he did not experience any additional search-related trials. Note that according to Chapman (1987), mirror recognition tasks require a higher level of cognitive ability than object permanence tasks (the former require the coordination of four sensorimotor schemes whereas the latter require combining two schemes with only a doubling of a third); thus, it seems that mirror tasks are unlikely to provide training for object permanence tasks. Of course mirror trials might, simply because they also provided a break in the general routine, have somehow acted as a general energizer of all responses that might be emitted in other situations.

${ }^{14}$ We note that Task 16 abilities may be widespread in the animal kingdom. Comparable behavior may have already been demonstrated in certain avian species: Chickadees (Pants alricapillus) that cache two different types of food recover their favorite food first, suggesting memory for the particular type of food rather than merely for something edible (Sherry, 1984). 


\section{REFERENCES}

Antinucci, F. (1990). The theoretical framework. In F. Antinucci (Ed.), Cognitive structure and development in nonhuman primates (pp. 11-17). Hillsdale, NJ: Erlbaum.

Antinucci, F., Spinozzi, G., Visalberghi, E., \& Volterra, V. (1982). Cognitive development in a Japanese macaque (Macaco fuscata). Istituto Superiore di Sanita Annali, 2, 177-184.

Baillargeon, R. (1986). Representing the existence and the location of hidden objects: Object permanence in 6- and 8-month-old infants. Cognition, 23, 21-41.

Baillargeon, R. (1987). Object permanence in $3 \frac{1 / 2-}{2}$ and $41 / 2$-month-old infants. Developmental Psychology, 23, 655-664.

Baillargeon, R., \& DeVos, J. (1991). Object permanence in young infants: Further evidence. Child Development, 62, 1226-1246.

Baillargeon, R., Spelke, E. S., \& Wasserman, S. (1985). Object permanence in five-month-old infants. Cognition, 20, 191-208.

Bateson, P. (1979). How do sensitive periods arise and what are they for? Animal Behaviour, 27, 470486.

Bjork, E. L., \& Cummings, E. M. (1984). Infant search errors: Stage concept development or stage memory development. Memory \& Cognition, 12, 1-19.

Bower, T. G. R. (1982). Development in infancy. San Francisco: W. H. Freeman.

Bremmer, J. G. (1978a). Egocentric versus allocentric spatial coding in nine-month-old infants: Factors influencing choice of code. Developmental Psychology, 14, 346-355.

Bremmer, J. G. (1978b). Spatial errors made by infants: Inadequate spatial cues or evidence of egocentrism. British Journal of Psychology, 69, 77-84.

Bruner, J. S. (1964). The course of cognitive development. American Psychologist, 19, 1-16.

Butterworth, G., Jarrett, N., \& Hicks, L. (1982). Spatiotemporal identity in infancy: Perceptual competence or conceptual deficit? Developmental Psychology, IS, 435-449.

Chapman, M. (1987). A longitudinal study of cognitive representation in symbolic play, self-recognition, and object permanence during the second year. International Journal of Behavioural Development, 10, 151-170.

Chevalier-Skolnikoff, S. (1976). The ontogeny of primate intelligence and its implications for communicative potential: A preliminary report. In S. R. Hamad, H. D. Steklis, \& J. Lancaster (Eds.), Annals of the New York Academy of Sciences: Vol. 280. Origins and evolution of language and speech (pp. 173-211). New York: New York Academy of Sciences.

Cornell, E. H. (1978). Learning to find things: A reinterpretation of object permanence studies. In L. S. Siegel \& C. J. Brainerd (Eds.), Alternatives to Piaget: Critical essays on the theory (pp. 1-10). New York: Academic Press.

de Blois, S. T., \& Novak, M. A. (1994). Object permanence in rhesus monkeys (Macaco mulatto). Journal of Comparative Psychology, 108, 318-327.

Diamond, A. (1990a). Developmental time course in human infants and infant monkeys, and the neural basis of, inhibitory control of reaching. In A. Diamond (Ed), Annals of the New York Academy of Sciences: Vol. 608. The development and neural bases of higher cognitive functions (pp. 637669). New York: New York Academy of Sciences.

Diamond, A. (1990b). The development and neural bases of memory functions as indexed by the $A B$ and delayed response tasks in human infants and infant monkeys. In A. Diamond (Ed.), Annals of the New York Academy of Sciences: Vol. 608. The development and neural bases of higher cognitive functions (pp. 267-309). New York: New York Academy of Sciences.

Doré, F. Y. (1986). Object permanence in adult cats (Felis catus). Journal of Comparative Psychology, 100, 340-347. 
Doré, F. Y. (1990). Search behaviour of cats (Felis catus) in an invisible displacement test: Cognition and experience. Canadian Journal of Psychology, 44, 359-370.

Doré, F. Y. (1991). Search behaviour of cats in an invisible displacement test: Object permanence and retroactive interference. Cahiers de recherche de l'Ecole de Psychologic (Universite Laval), 117.

Doré, F. Y., \& Dumas, C. (1987). Psychology of animal cognition: Piagetian studies. Psychological Bulletin, 102, 219-233.

Doré, F. Y., Fiset, S., Goulet, S., Dumas, M.-C., \& Gagnon, S. (1996). Search behavior in cats and dogs: Interspecific differences in working memory and spatial cognition. Animal Learning \& Behavior, 24, 142-149.

Dumas, C. (1992). Object permanence in cats (Felis catus): An ecological approach to the study of invisible displacements. Journal of Comparative Psychology, 106, 404-410.

Dumas, C., \& Brunei, C. (1994). Permanence de l'objet chez le singe capucin (Cebus apella): Etude de deplacements invisibles [Object permanence in capuchin monkeys: A study of invisible displacements]. Canadian Journal of Experimental Psychology, 48, 341-358.

Dumas, C., \& Doré, F. Y. (1989). Cognitive development of kittens: A cross-sectional study of object permanence. Journal of Comparative Psychology, 103, 191-200.

Dumas, C., \& Doré, F. Y. (1991). Cognitive development in kittens (Felis catus): An observational study of object permanence and sensorimotor intelligence. Journal of Comparative Psychology, 105, 357365.

Dumas, C., \& Wilkie, D. M. (1995). Object permanence in ring doves (Streptopelia risoria). Journal of Comparative Psychology, 109, 142-150.

Etienne, A. S. (1973a). Developmental stages and cognitive structures as determinants of what is learned. In R. A. Hinde \& J. Stevenson (Eds.), Constraints on learning (pp. 371-395). New York: Academic Press.

Etienne, A. S. (1973b). Searching behavior towards a disappearing prey in the domestic chick as affected by preliminary experience. Animal Behaviour, 21, 749-761.

Flavell, J. H. (1985). Cognitive development. Englewood Cliffs, NJ: Prentice-Hall.

Funk, M. S. (1996). Development of object permanence in the New Zealand parakeet (Cyanoramphus auriceps). Animal Learning \& Behavior, 24, 375-383.

Gagnon, S., \& Doré, F. Y. (1992). Search behavior in various breeds of adult dogs (Canis familiaris): Object permanence and olfactory cues. Journal of Comparative Psychology, 106, 58-68.

Gagnon, S., \& Doré, F. Y. (1993). Search behavior of dogs (Canis familiaris) in invisible displacement problems. Animal Learning \& Behavior, 21, 246-254.

Gagnon, S., \& Doré, F. Y. (1994). Cross-sectional study of object permanence in domestic puppies (Canis familiaris). Journal of Comparative Psychology, 108, 220-232.

Gardner, B. T., \& Gardner, R. A. (1975). Evidence for sentence constituents in early utterances of child and chimpanzee. Journal of Experimental Psychology: General, 104, 244-267.

Goldfield, E. C., \& Dickerson, D. J. (1981). Keeping track of locations during movement in 8- to 10-monthold infants. Journal of Experimental Child Psychology, 32, 48-64.

Goulet, S., Doré, F. Y., \& Lehotkay, R. (1996). Activations of locations in working memory in cats. Quarterly Journal of Experimental Psychology, 49B, 81-92.

Goulet, S., Doré, F. Y., \& Rousseau, R. (1994). Object permanence and working memory in cats (Felis catus). Journal of Experimental Psychology: Animal Behavior Processes, 20, 347-365.

Gruber, H. E., Girgus, J. S., \& Banuazizi, A. (1971). The development of object permanence in the cat. Developmental Psychology, 4, 9-15.

Hallock, M. B., \& Worobey, J. (1984). Cognitive development in chimpanzee infants (Pan troglodytes). Journal of Human Evolution, 13, 441-447.

Harriman, A., \& Berger, R. (1986). Olfactory acuity in the common raven (Can/us corax). Physiology and Behavior, 36, 257-262. 
Harris, P. L. (1973). Perseverative errors in search by young infants. Child Development, 44, 28-33.

Harris, P. L. (1975). Development of search and object permanence during infancy. Psychological Bulletin, 82, 332-344.

Harris, P. L. (1983). Infant cognition. In M. M. Haith \& J. J. Campos (Eds.), Handbook of child psychology: Infancy and developmental psychobiology (Vol. 2, pp. 689-782). New York: Wiley.

Hediger, H. K. P. (1981). The Clever Hans phenomenon from an animal psychologist's point of view. In T. A. Sebeok \& R. Rosenthal (Eds.), Annals of the New York Academy of Sciences: Vol. 364. The Clever Hans phenomenon: Communication with horses, whales, apes, and people (pp. 1-17). New York: New York Academy of Sciences.

Kohler, W. (1976). The mentality of apes. New York: Liveright. (Original work published 1927)

Kroodsma, D. E. (1982). Learning and the ontogeny of sound signals in birds. In D. E. Kroodsma \& E. H. Miller (Eds.), Acoustic communication in birds: Vol. 2. Song learning and its consequences (pp. 123). New York: Academic Press.

LeCompte, G. K., \& Gratch, G. (1972). Violation of a rule as a method of diagnosing infants' levels of object concept. Child Development, 43, 385-396.

Macphail, E. (1982). Brain and intelligence in vertebrates. Oxford: Oxford University Press.

Macphail, E. (1987). The comparative psychology of intelligence. Behavioral and Brain Sciences, 10, 645695.

Mathieu, M., \& Bergeron, G. (1981). Piagetian assessment of cognitive development in chimpanzees (Pan troglodytes). In A. B. Chiarell \& R. S. Corrucini (Eds.), Primate behavior and sociobiology (pp. 142-147). Berlin: Springer-Verlag.

Mathieu, M., Bouchard, M.-A., Granger, L., \& Herscovitch, J. (1976). Piagetian object-permanence in Cebus capucinus, Lagothrica flavicauda, and Pan troglodytes. Animal Behaviour, 24, 585-588.

Meltzoff, A. N. (1988). Imitation, objects, tools and the rudiments of language in human ontogeny. Human Evolution, 3, 45-64.

Miller, R. E., \& Murphy, J. V. (1964). Influence of the spatial relationships between the cue, reward, and response in discrimination learning. Journal of Experimental Psychology, 67, 120-123.

Natale, F., \& Antinucci, F. (1989). Stage 6 object-concept and representation. In F. Antinucci (Ed.), Cognitive structure and development in nonhuman primates (pp. 97-112). Hillsdale, NJ: Erlbaum.

Natale, F., Antinucci, F., Spinozzi, G., \& Poti, P. (1986). Stage 6 object-concept and representation in nonhuman primate cognition: A comparison between gorilla (Gorilla gorilla gorilla) and Japanese macaque (Macaco fuscata). Journal of Comparative Psychology, 100, 335-339.

Parker, S. T. (1977). Piaget's sensorimotor series in an infant macaque: A model for comparing unstereotyped behavior and intelligence in human and nonhuman primates. In S. ChevalierSkolnikoff \& F. E. Poirier (Eds.), Primate bio-social development: Biological, social and ecological determinants (pp. 43-112). New York: Garland.

Parker, S. T. (1990). Origins of comparative developmental evolutionary studies of primate mental abilities. In S. T. Parker \& K. R. Gibson (Eds.), "Language " and intelligence in monkeys and apes (pp. 3-64). Cambridge, England: Cambridge University Press.

Pepperberg, I. M. (1992). Proficient performance of a conjunctive, recursive task by an African grey parrot (Psittacus erithacus). Journal of Comparative Psychology, 106, 295-305.

Pepperberg, I. M., \& Funk, M. S. (1990). Object permanence in four species of psittacine birds: An African grey parrot (Psittacus erithacus), an Illiger mini macaw (Ara maracana), a parakeet (Melopsittacus undulatus), and a cockatiel (Nymphicus hollandicus). Animal Learning \& Behavior, 18, 97-108.

Pepperberg, I. M., Garcia, S. E., Jackson, E. C., \& Marconi, S. (1995). Mirror use by African grey parrots (Psittacus erithacus). Journal of Comparative Psychology, 109, 182-195.

Pepperberg, I. M., \& Kozak, F. A. (1986). Object permanence in the African grey parrot (Psittacus erithacus). Animal Learning \& Behavior, 14, 322-330. 
Pepperberg, I. M., Willner, M. R., Gupta, S. K., \& Meister, M. (1996). [Mirror use by a juvenile grey parrot]. Unpublished raw data.

Piaget, J. (1952). The origins of intelligence in children (M. Cook, Trans.). New York: International Universities Press. (Original work published 1936)

Piaget, J. (1954). The construction of reality in the child. (M. Cook, Trans.). New York: Basic Books. (Original work published 1937)

Poll, P. (1989). Early sensorimotor development in macaques (Macaco fuscata, Macaco fascicularis). In F. Antinucci (Ed.), Cognitive structure and development in nonhuman primates (pp. 39-53). Hiilsdale, NJ: Erlbaum.

Rakic, P., Bourgeois, J.-P., Zecevic, N., Eckenhoff, M. F., \& Goldman-Rakic, P. S. (1986). Concurrent overproduction in synapses in diverse regions of the primate cerebral cortex. Science, 232, 232235.

Redshaw, M. (1978). Cognitive development in human and gorilla infants. Journal of Human Evolution, 7 , 133-141.

Schino, G., Spinozzi, G., \& Berlinguer, L. (1990). Object concept and mental representation in Cebus apella and Macaco fascicularis. Primates, 31, 537-544.

Sherry, D. F. (1984). Food storage by black-capped chickadees: Memory for the location and contents of caches. Animal Behaviour, 32, 451-464.

Sophian, C. (1985). Understanding the movement of objects: Early developments in spatial cognition. British Journal of Developmental Psychology, 3, 321-333.

Sophian, C., \& Sage, S. (1983). Development in infants' search for displaced objects. Journal of Experimental Child Psychology, 35, 143-160.

Spinozzi, G. (1989). Early sensorimotor development in Cebus (Cebus apella). In F. Antinucci (Ed.), Cognitive structure and development in nonhuman primates (pp. 55-66). Hiilsdale, NJ: Erlbaum.

Spinozzi, G., \& Natale, F. (1989). Early sensorimotor development in gorilla. In F. Antinucci (Ed.), Cognitive structure and development in nonhuman primates (pp. 21-38). Hiilsdale, NJ: Erlbaum.

Steckol, K. F., \& Leonard, L. B. (1981). Sensorimotor development and the use of prelinguistic performatives. Journal of Speech and Hearing Research, 24, 262-268.

Stettner, L. J., \& Matyniak, K. (1968). The brain of birds. Scientific American, 218, 64-76.

Thinus-Blanc, C., Poucet, B., \& Chapuis, N. (1982). Object permanence in cats: Analysis in locomotor space. Behavioural Processes, 7, 81-86.

Thinus-Blanc, C., \& Scardigli, P. (1981). Object permanence in the golden hamster. Perceptual and Motor Skills, 53, 1010.

Thomas, R. K., \& Walden, E. L. (1985). The assessment of cognitive development in human and nonhuman primates. In E. Watts (Ed.), Nonhuman primate models for human growth and development (pp. 187-215). Atlanta, GA: Alan R. Liss.

Tinklepaugh, O. T. (1928). An experimental study of representative factors in monkeys. Journal of Comparative Psychology, 8, 197-236.

Tinklepaugh, O. T. (1932). Multiple delayed reaction with chimpanzees and monkeys. Journal of Comparative Psychology, 13, 207-243.

Tomasello, M., \& Farrar, M. J. (1984). Cognitive bases of lexical development: Object permanence and relational words. Journal of Child Language, 11, 477-493.

Tomasello, M., \& Farrar, M. J. (1986). Object permanence and relational words: A lexical training study. Journal of Child Language, 13, 495-505.

Tomasello, M., Savage-Rumbaugh, E. S., \& Kruger, A. C. (1993). Imitative learning of actions on objects by children, chimpanzees, and enculturated chimpanzees. Child Development, 64, 1688-1705.

Triana, E., \& Pasnak, R. (1981). Object permanence in cats and dogs. Animal Learning \& Behavior, 9, 135-139. 
Uzgiris, I. C., \& Hunt, J. (1966). Ordinal scales of infant development: No. 1. Object permanence [film]. Champaign: University of Illinois.

Uzgiris, I. C., \& Hunt, J. (1975). Assessment in infancy: Ordinal scales of psychological development. Champaign: University of Illinois Press.

Vaughter, R. M., Smotherman, W., \& Ordy, J. M. (1972). Development of object permanence in the infant squirrel monkey. Developmental Psychology, 7, 34-38.

Wadsworth, B. J. (1984). Piaget's theory of cognitive and affective development. New York: Longman.

Wellman, H. M., Cross, D., \& Bartsch, K. (1986). Infant search and object permanence: Meta-analysis of the A-not-B error. Monographs of the Society for Research in Child Development, 57(3, Serial No. 214).

Wenzel, B. M. (1967). Olfactory perception in birds. In T. Hayashi (Ed.), Olfaction and taste (pp. 203-217). Oxford, England: Pergamon Press.

Wise, K. L., Wise, L. A., \& Zimmermann, R. R. (1974). Piagetian object permanence in the infant rhesus monkey. Developmental Psychology, 10, 429-437.

Wishart, J. G., \& Bower, T. G. (1985). A longitudinal study of the development of the object concept. British Journal of Developmental Psychology, 3, 243-258.

Wood, S., Moriarty, K. M., Gardner, B. T., \& Gardner, R. A. (1980). Object permanence in child and chimpanzee. Animal Learning \& Behavior, 8, 3-9. 